\title{
A CONTROL SYSTEM FOR X-RAY DIFFRACTOMETER SCANNING
}

L. H. COOK, JR.

RE GOR D

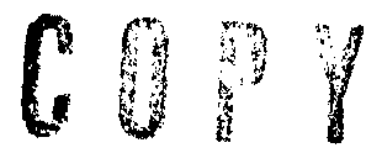

DO NOT RELEASE FROM FILE

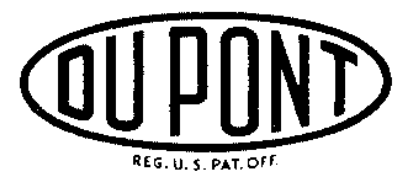

Savannah River Laboratory

Aiken, South Carolina 


\section{LEGAL NOTICE}

This report was prepared as an account of Government sponsored work. Nelther the United States, nor the Commission, nor any person acting on behalf of the Commission:

A. Makes any warranty or representation, expressed or implfed, with respect to the accuracy, completeness, or usefulness of the information contained in this report, or that the use of any information, apparatus, method, or process disclosed in this report may not infringe privately owned rights; or

B. Assumes any liabilities with respect to the use of, or for damages resulting from the use of any information, apparatus, method, or process disclosed in this report.

As used in the above, "person acting on behalf of the Commission" includes any employee or contractor of the Commission, or employee of such contractor, to the extent that such employee or contractor of the Commission, or employee of such contractor prepares, disseminates, or provides access to, any information pursuant to his employment or contract with the Commission, or his employment with such contractor.

Printed in USA. Price \$1.00

Available from the Clearinghouse for Federal Scientific

and Technical Information, National Bureau of Standards,

U. S. Department of Commerce, Springfield, Va. 22151 


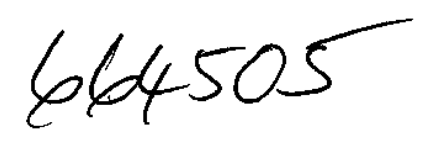

DP-900

Instruments

(TID-4500)

\title{
A CONTROL SYSTEM FOR $X$-RAY DIFFRACTOMETER SCANNING
}

\author{
by \\ L. H. Cook, Jr. \\ Approved by \\ D. E. Waters, Manager \\ Laboratory Operations and Services Division
}

August 1966

E. 1. DU PONT DE NEMOURS \& COMPANY

SAVANNAH RIVER LABORATORY

AIKEN, S. C. 29801

CONTRACT AT(07.2)-1 WITH THE

UNITED STATES ATOMIC ENERGY COMMISSION 


\begin{abstract}
A time-based program controller using a prepunched tape was developed for automatic goniometer scanning of an X-ray diffractometer in which the locations of the diffraction lines are known. The program controller consists of (1) a dual-speed drive unit which moves the gonlometer rapldiy over portions of the diffraction pattern not under observation and slowly over the diffraction lines to be observed, and (2) an electronic control system which will scan the selected diffraction lines, print the accumulated data for each line, reset the gonlometer, rewind the control tape, and then elther stop or repeat the cycle. The control accuracy is within $0.01^{\circ}$ Bragg $2 \theta$ angle.
\end{abstract}




\section{CONTENTS}

Page

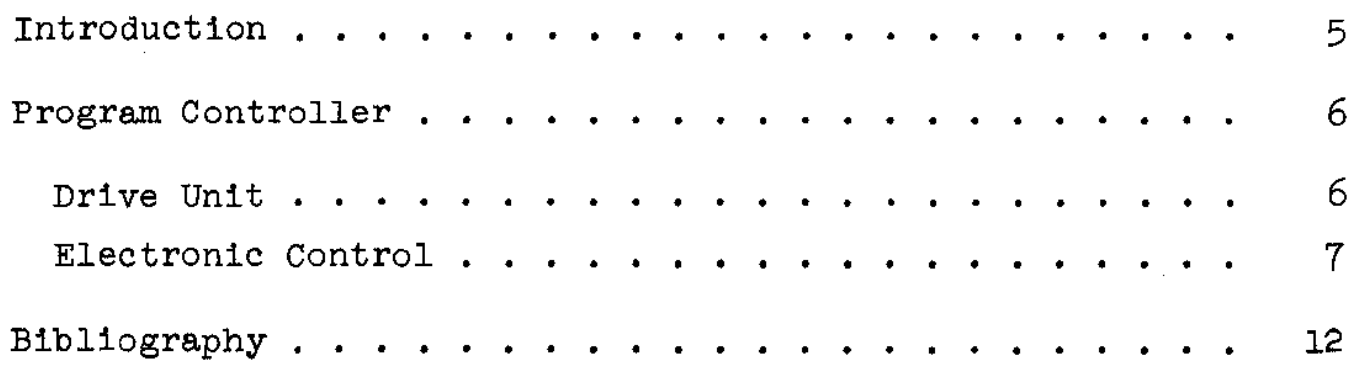

\section{LIST OF FIGURES}

\section{Figure}

1 X-ray Program Controller with Norelco Diffractometer . . . . . . . . . . 5

2 Goniometer Drive Unit ......... 6

3 Block Dlagram of the X-ray Program Controller . . 7

4 Tape Channel Identification . . . . . . 7

5 Control Circuit Diagram . . . . . . . . 9

6 Serial Converter Diagram .......... 10 


\section{A CONTROL SYSTEM FOR \\ $X$-RAY DIFFRACTOMETER SCANNING}

\section{INTRODUCTION}

Crystallographic data from a large number of uranium samples are routinely analyzed in the laboratory. Because the accumulation of $\mathrm{X}$-ray data is time consuming and tedious, an automat1c system was deslred whlch would control the gonlometer scanning function and record the data.

Th1s paper discusses a program controller which was developed as an automatic time-based accessory to be used with a Norelco X-ray diffractometer when analyzing material in which the location of the aiffraction lines are known (F1gure 1).

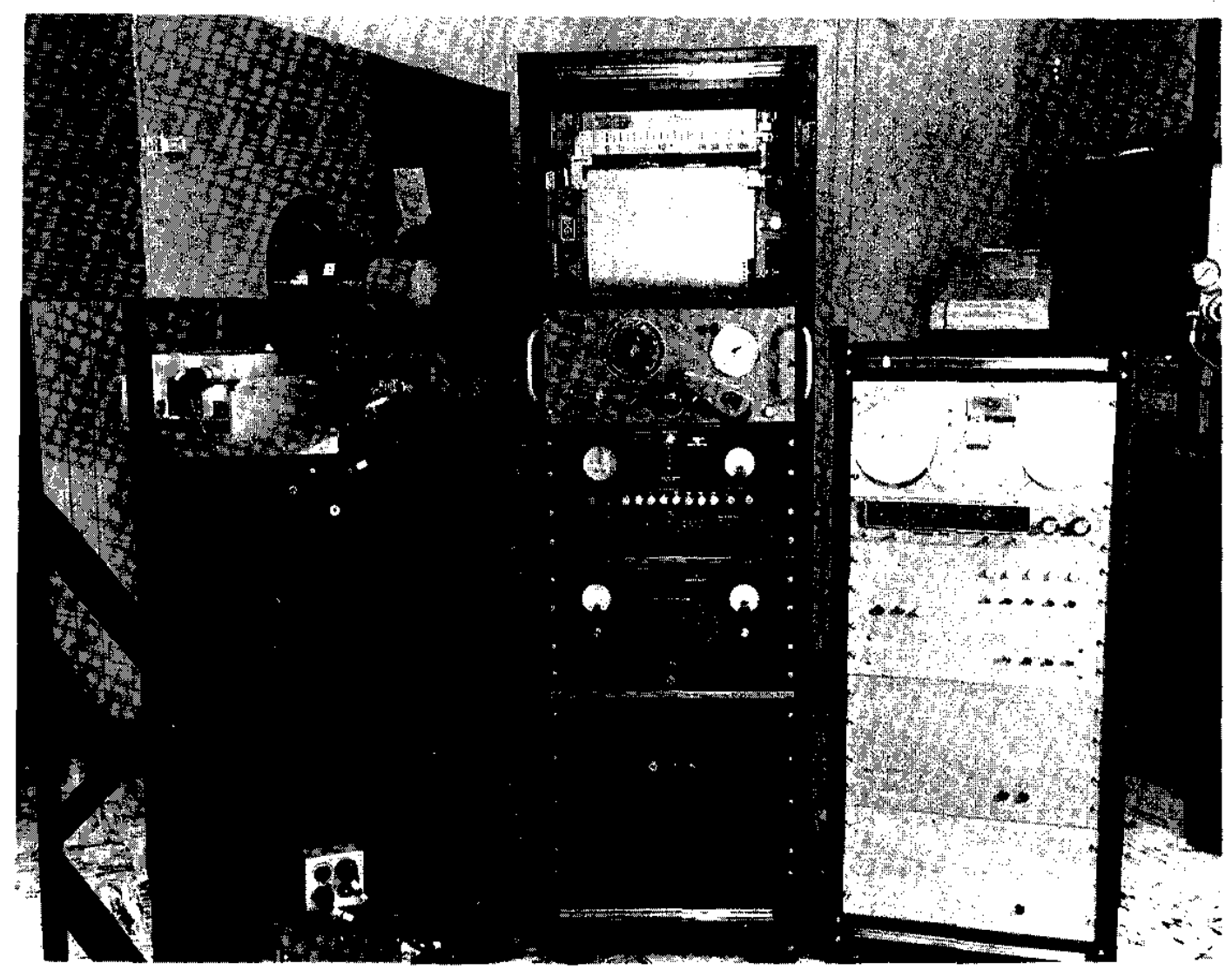

FIG. 1 X-RAY PROGRAM CONTROLLER WITH NORELCO DIFFRACTOMETER 


\section{PROGRAM CONTROLLER}

The program controller consists of a dual-speed drive unit that attaches directly to the wide-range goniometer and an electronic control system. All controller operations are programmed through a five-channel code on eight-channel paper tape.

\section{Drive Unit}

The drive unit (Figure 2) is a synchronous arive motor with two output gear ratios. The desired speed is selected by energizing the proper magnetic clutch coupling. The Norelco gears couple the drive unit to the wide-range goniometer (Figure 2). The output shaft rotates at $30 \mathrm{rpm}$ on high speed and at 2 rpm on slow speed.

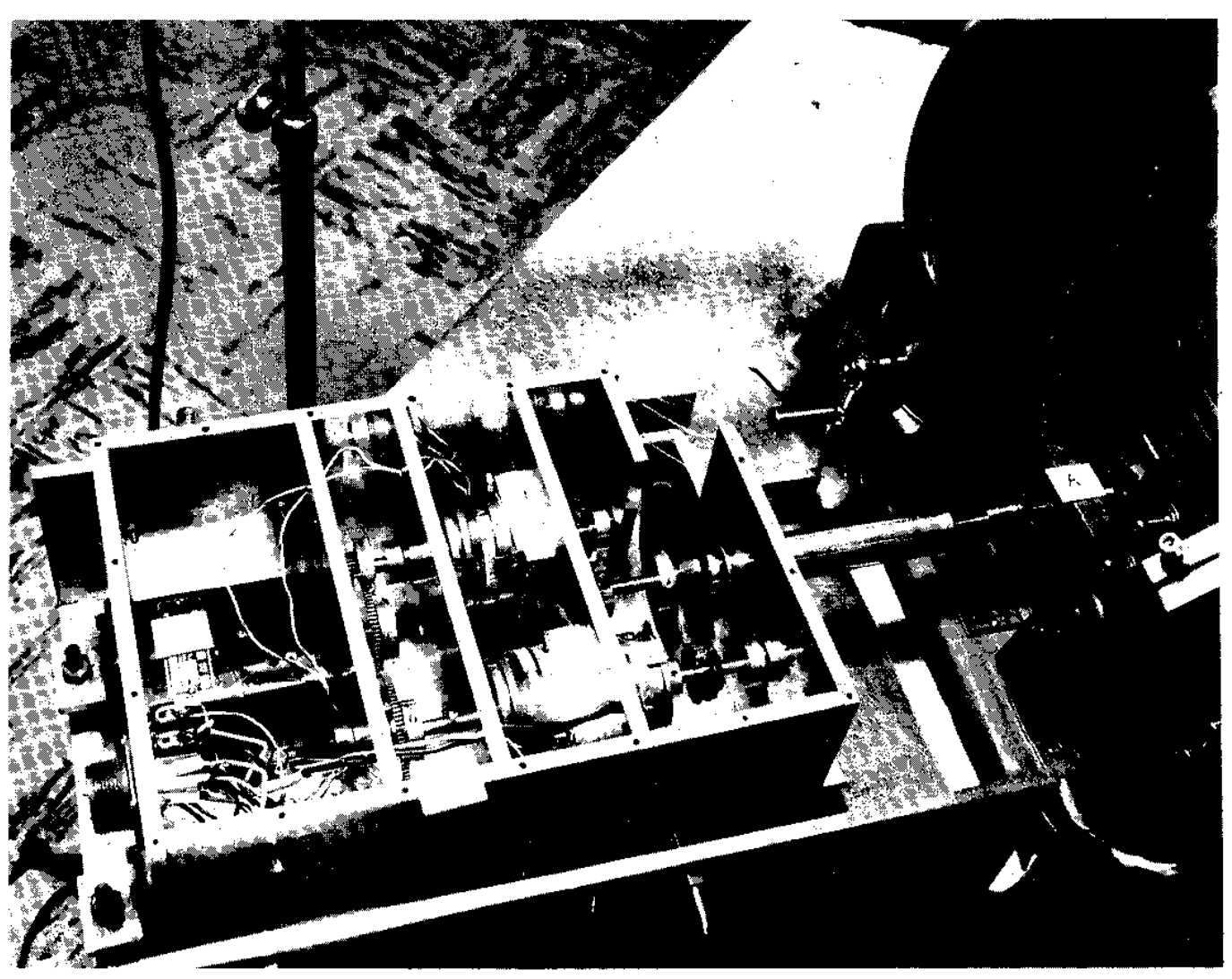

FIG. 2 GONIOMETER DRIVE UNIT

A magnetic brake prevents goniometer movement during certain instrument operations. Circuit interlocks prevent energizing both the brake and a clutch coupling simultaneously. 


\section{Electronic Control}

The electronic control equipment shown in Figure 1 consists of a tape reader, dual pulser, scaler, serial converter, master control, scanning pulser, and data printer. These are shown in the block diagram in Figure 3.

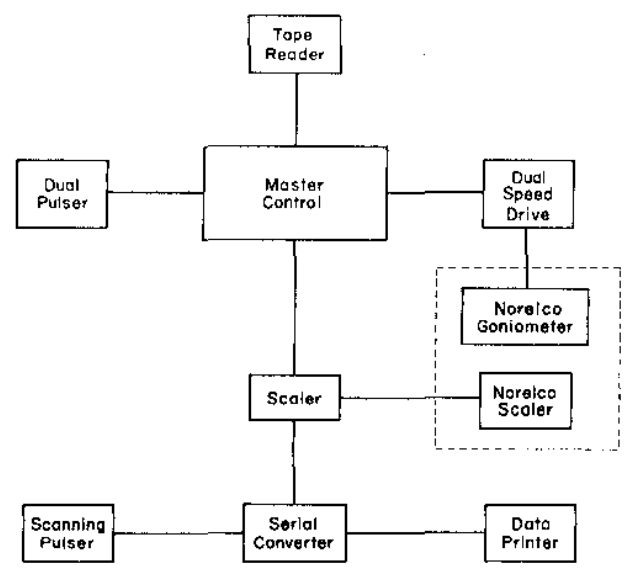

FIG. 3 BLOCK DIAGRAM OF THE X-RAY PROGRAM CONTROLLER

Diffraction lines are selected for scanning, and the codes for the various operations are punched into the control tape. The control tape is a one-inch-wlde, elght-channel tape; however only five channels are used. The tape code and feed holes are In line and spaced 0.1 inch between centers. The location of each channel on the tape is shown in Figure 4. The code channels and corresponding functions are:

$\begin{array}{cl}\text { Channel } & \text { Instrument Operated } \\ 1 & \text { Goniometer Drive } \\ 2 & \text { Goniometer Speed } \\ 3 & \text { Goniometer Direction } \\ 4 & \text { Print Cycle } \\ 5 & \text { Tape Rewind }\end{array}$

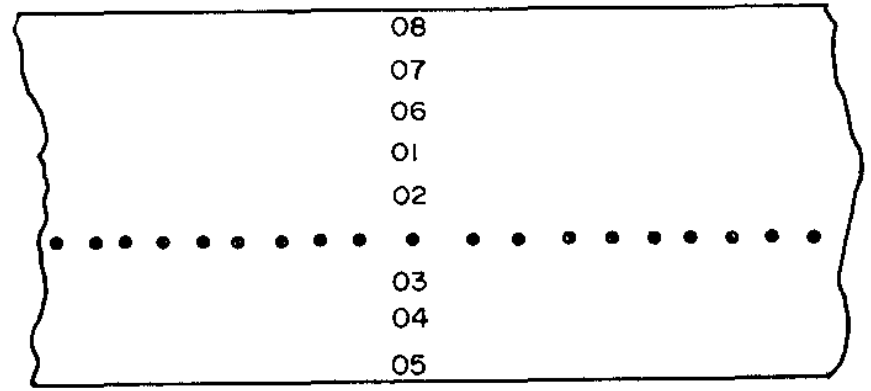

FIG. 4 TAPE CHANNEL IDENTIFICATION 
Pulses generated at a rate of six per second by a phototube and relay in the dual pulser move the tape through the tape reader at a constant speed. A second pulse rate of 36 pulses per second is also available from the dual pulser to rewind the program tape. The tape reader detects signals resulting from the holes punched in the tape and sends them to the master control unit. With these signals, the master unit can now initiate operation of the other equipment in the electronic control system at the appropriate time.

When the START switch is pressed, operate relay, RI 114 , (Figure 5) energizes the tape reader motor, the tape drive colls, and tise read contacts. The relay is self-holding and will remain energized until the STOP switch is pressed or the automatic program is complete.

A code hole in channel 1 of the tape will momentarily close the corresponding read contact, thereby actuating relay $R Y 101$ (Figure 5), which energizes the drive control relay, RY 106. The drive relay is a bi-stable, cam-operated type that remains in one state until power is momentarily applied to shift states. Actuating this relay lights the DRIVE indicator, releases the magnetic brake, and applies power to the high-speed magnetic clutch coupling in the drive mechanism.

A code hole in channel 2 actuates (through RY 102) the bi-stable speed control relay, RY 107, which lights the SCAN indicator, changes the power from the high-speed to the slowspeed magnetic clutch coupling, and opens the input gate to the scaler. Thus, code holes in channels 1 and 2 direct the instrument to move the goniometer at a slow speed and to accumulate the count data from the $\mathrm{X}$-ray detector.

At the end of the desired scan time, code holes in channels 1 and 2 are necessary to return both relays RY 106 and RY 107 to normal. There, the scaler gate closes, and the goniometer brake is applied.

A code hole in channel 4 initiates the print cycle by momentarily closing the print relay, RY 104, which energizes the serial converter unit shown in Figure 6. The stepping switch, RY 213, is actuated and scans data stored in the scaler. The scaler decades are scanned from left to right, i.e., the most significant tube first. Sufficient voltage is available from the lighted scaler numeral to actuate the control circuit for the digit solenoids of the printer mechanism. The operating sequence is the same as that of a 10-key adding machine. The units digit is not determined from the scaler tube, but is fixed at 5 . After 


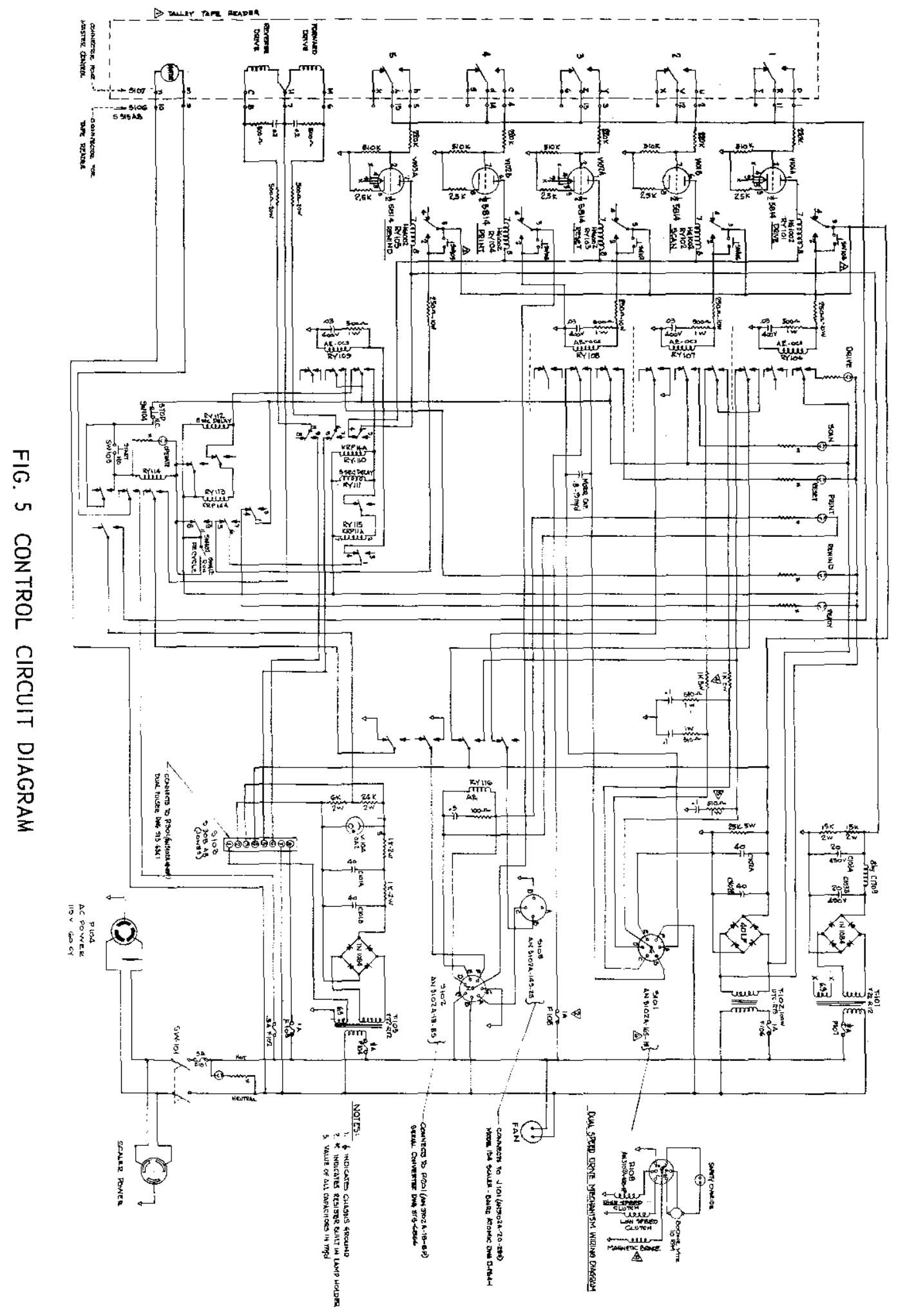




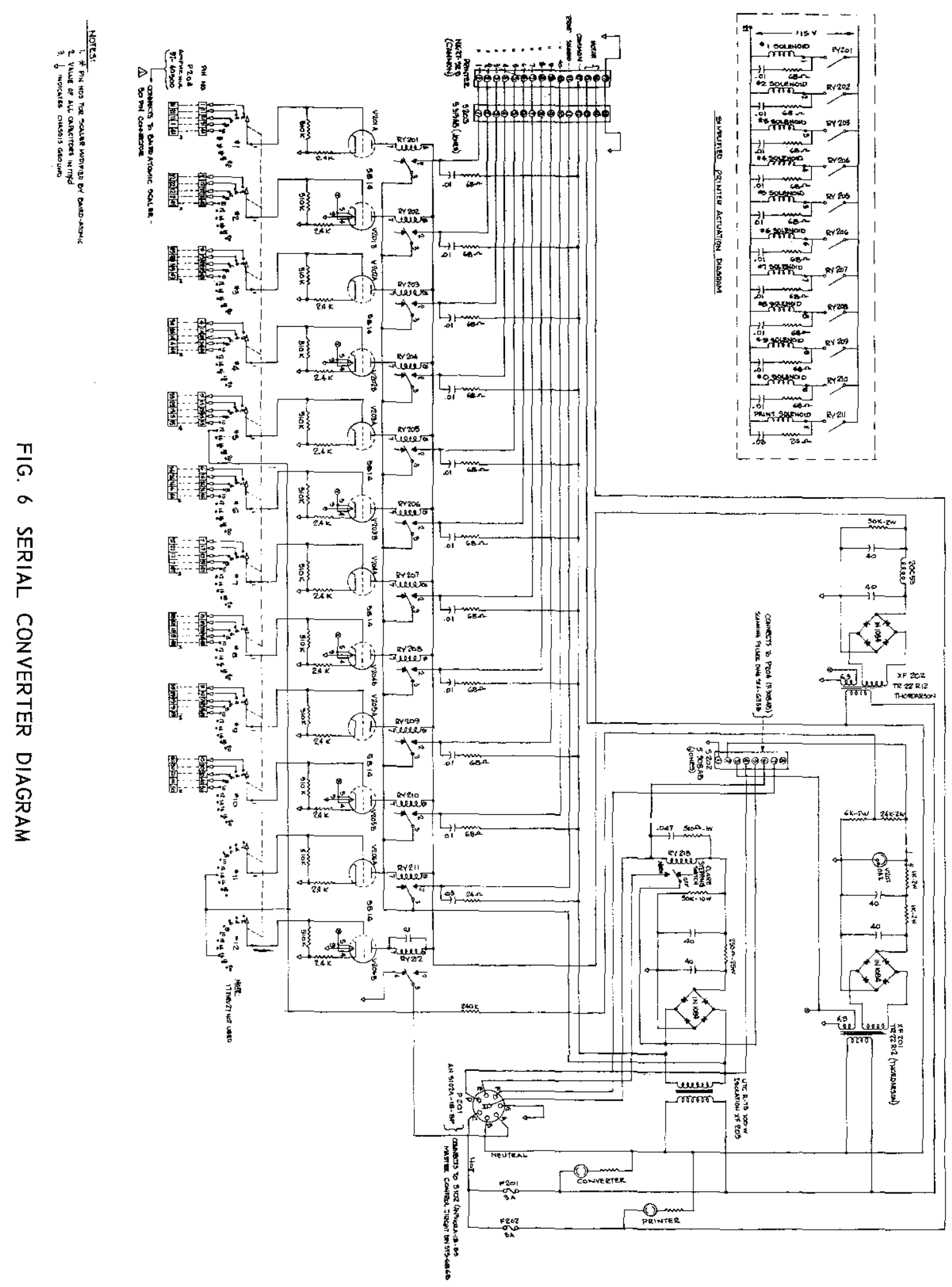


scanning all scaler decades, the print solenoid is energized to register the digits entered into the printer mechanism, and the scaler is reset.

After the inftial pulse from the master control circuit, the stepping. switch movement is controlled by the scanming puiser. This small photoelectric pulser is a plug-in unit on the serial converter. A rotating disk driven by a small synchronous motor generates the light pulses to move the stepping switch at 600 steps per minute. Each time a pulse falls on the phototube, an amplifier closes a relay, which actuates the stepping switch.

An off-normal contact on the stepping switch energizes relay RY 116 until the printing cycle is completed. Several functions are interlocked through the contacts on this relay. The scaler gate is closed so no additional counting can take place until the print cycle is completed. The tape reader drive coils are deactivated to prevent the reading of additional control signals. The magnetic brake in the drive unit is applied during this period. The stepping switch is interlocked and will stop at the end of its cycle. The PRINT light is also energized during the print cycle.

A code hole in channel 3 energizes the bi-stable reset relay, RY 108. Actuating this relay reverses the goniometer drive motor. The circuit connections are such that when the RESET indicator light is on, the goniometer moves toward smaller values of $2 \theta$. The normal scan direction is toward larger $2 \theta$ angles. Circuit interlock connections require that the drive relay RY 106, must be actuated to release the magnetic brake.

After the program has been completed, the control tape is rewound when a hole in channel 5 energizes the bi-stable relay, RY 109. This relay energizes the tape reader reverse drive coll at 36 pulses per second and lights the REWIND indicator. (Circult interlocks prevent the control slgnals from being read in reverse). Time delay relays RY 111 and RY 112 momentarily de-energize channel 5 to allow reversing of the tape reader mechanism. A channel 5 code must also appear at the beginning of the tape before the start of the scan program.

After the program has been completed and the tape rewound, a contact on $\mathrm{RY} 112$ releases the operate relay and stops the program, unless the switch has been placed in the RECYCLE position, in which case the program w1ll be repeated. 
All AC input power, except to the scaler unit, is controlled by the switch on the master control panel. The scaler is separately controlled and may be left on standby. Background counts and step-scanning operations can be programmed.

\section{BIBLIOGRAPHY}

1. E. R. P1ke and J. W. Hughes. "Monltored Gelger Counter X-Ray Diffractometer with Automatic Recording." J.Sci. Instr. 36, 212 (1959).

2. S. C. Abrams. "Programmed Electronic X-Ray Automatic Diffractometer." Rev. Sc1. Instr. 33, 973 (1962).

3. H. Cole, Y. Okaya, and F. W. Chambers. "Computer-Controlled Diffractometer." Rev. Sci. Instr. 34, 872 (1963). 